\title{
Implementing Quantitative Literacy at Southwestern Community College, North Carolina
}

\author{
Vicki Todd \\ Southwestern Community College \\ John Wagaman \\ Western Carolina University, jcwagaman@wcu.edu
}

Follow this and additional works at: https://digitalcommons.usf.edu/numeracy

Part of the Community College Leadership Commons, and the Science and Mathematics Education Commons

\section{Recommended Citation}

Todd, Vicki, and John Wagaman. "Implementing Quantitative Literacy at Southwestern Community College, North Carolina." Numeracy 8, Iss. 2 (2015): Article 9. DOI: http://dx.doi.org/10.5038/ 1936-4660.8.2.9 


\title{
Implementing Quantitative Literacy at Southwestern Community College, North Carolina
}

\begin{abstract}
There is a time when articulation agreements between universities and community colleges come to an end. When this happened in North Carolina, there was great hope that not only would the mathematics classes that were offered in the North Carolina Community College System be revamped with respect to overlapping content, but also that mathematics classes would be developed that have a clear connection between what is seen in the world and what is taught in the classroom especially for non-STEM (science, technology, engineering, and mathematics-related studies) students. This paper describes how Southwestern Community College (SCC) implemented a quantitative literacy class as it is now described in the newly adopted articulation agreement between the University of North Carolina (UNC) System and the North Carolina Community College System (NCCCS), why such a class was chosen to be in that articulation agreement from the standpoint of SCC, and the success that was seen from such an endeavor. Results of preliminary statistical analysis suggest that students enrolled in the new Quantitative Literacy (MAT 143) course performed better on a quantitative reasoning assessment, on average, than their peers enrolled in similar traditional courses at SCC.
\end{abstract}

\section{Keywords}

quantitative literacy, North Carolina Community College System, analysis of covariance

\section{Creative Commons License}

\section{cc) (i) (8)}

This work is licensed under a Creative Commons Attribution-Noncommercial 4.0 License

\section{Cover Page Footnote}

Vicki Todd is a faculty mathematics instructor at Southwestern Community College (SCC), Sylva, NC. She has taught a wide variety of courses including Quantitative Literacy, Statistics, College Algebra, PreCalculus, Mathematical Modeling, and Developmental Mathematics. She has been teaching Quantitative Literacy since 2013 and is now the lead instructor for Quantitative Literacy at SCC.

John C. Wagaman, PhD, is an Assistant Professor of Mathematics at Western Carolina University, Cullowhee, NC. His research interests are in statistics education and applied statistics. 


\section{Introduction}

In the 1980s, a movement began towards a change in the teaching of mathematics. This was seen first as a nationwide push from the United States Department of Education (1983) with a landmark report A Nation at Risk, which called for all students to be able to apply mathematics in everyday situations. This trend continued into the following decade with a focus on quantitative literacy from the Mathematical Association of America (1994). More recently, the North Carolina Community College System (NCCCS 2014) had the opportunity to restructure its mathematics curriculum, which led to the involvement of the NCCCS with the quantitative literacy movement. Before the new quantitative literacy course was offered at every community college across the state, there were a few community colleges that had the opportunity to pilot the class as a substitute for the other mathematics classes that would either be no longer offered or would no longer exist as before. This paper describes the implementation of a new quantitative literacy course at Southwestern Community College (SCC) during this pilot process and analyzes its effectiveness.

\section{Background Information}

\section{The Importance of Quantitative Literacy}

The importance of quantitative literacy has been noted by a wide variety of higher education institutions, including relatively small institutions (e.g., Bressoud 2009; Steele and Kilic-Bahi 2010) and large research universities (e.g., Sikorskii et al. 2011). Quantitative literacy has been around informally since the framing of the Constitution but was lost as a formal teaching tool somewhere along the way (Cohen 2003). The Constitution enlisted three ideas that were quantitatively grounded: representative government, census of citizens, and census of noncitizen inhabitant slaves. The early writers of the Constitution also wanted to ensure that all citizens were educated. As the United States evolved into a more industrialized nation, the need for advanced mathematics became necessary for citizens in industries that required those skills (Cohen 2003). However, in the present workplace, only some $5 \%$ of jobs require advanced mathematics according to an estimate by Carnevale and Desrochers (2003).

The students enrolled in mathematics classes now include both STEM and non-STEM students, and they run the gamut of academic experience (Rocconi et al. 2013). Students enrolled in STEM programs still have the need for advanced mathematics classes, but that need is not as strong for non-STEM students who would benefit from mathematics or quantitative literacy that would apply to their lives more directly. The idea is not to have less mathematics but to have mathematical skills that lead to a better understanding of quantitative issues that are encountered in the world every day. 
To motivate the importance of quantitative literacy, one can consider the following: Is it preferable to have educated citizens who are able to differentiate a complex calculus function that is unrelated to their daily engagements or to have those citizens understand a statistical study about a medication that is prescribed for a family member? (Steen, 2001). The notion of quantitative literacy addresses these ideas but to go further would indicate a need for a definition of what exactly quantitative literacy is. The definition that best fits the NCCCS is "an aggregate of skills, knowledge, beliefs, dispositions, habits of mind, communication capabilities, and problem solving skills that people need in order to engage effectively in quantitative situations arising in life and work" (Steen, 2001). In other words, quantitative literacy is the ability to understand the use of numbers and data analysis in everyday situations. Quantitative literacy is less about the derivation of answers and more about the understanding of what those numbers mean. Quantitative literacy is not only important for a better quality of life, but also for success within our economy as it becomes ever more dependent on technology. Success in a more technology-based economy will require more quantitative skills where citizens are expected to apply mathematics in everyday situations (Carnevale and Desrochers 2003).

\section{North Carolina Community College System Redesign}

The state of North Carolina recognized the importance of quantitative literacy and its connection between the world and the classroom. When the opportunity arose to redesign the curriculum mathematics classes for the state of North Carolina, a Mathematics Curriculum Improvement Project (CIP) committee was formed with members from across the state of North Carolina (NCCCS 2012). The CIP committee redesigned the mathematics curriculum for the North Carolina Community College system and is now included in an articulation agreement with the University of North Carolina System. The decision to consolidate classes that overlapped in curriculum drove the restructuring of the classes that were taught. Instead of providing students with a potentially overwhelming number of choices for mathematics courses, the community college system designed three tracks, which were motivated by a categorization of the types of students who would matriculate from the system.

The first track (a certification track) is primarily for non-degree seeking students who are working towards certification in specific areas. Courses in this track are not designed to be transferrable to a university. The second track (a nonSTEM track) is for students seeking degrees in majors other than science, technology, engineering and mathematics, who are either pursuing an Associate in Arts (college transfer) or an Associate in Applied Science. The third track (a STEM track) is for STEM students. The third track is a calculus track that experienced little change at this time from the previous implementation with students who were mainly from STEM disciplines. It is the belief of the authors and many others that the landscape of the traditional calculus track should and will take a more quantitative reasoning approach (Gaze 2014). 
The creation of the certification and the non-STEM tracks drastically changed the community college mathematics course landscape in North Carolina. The premise for these two tracks from a mathematics perspective is to teach mathematics that students will need not only to be better at their jobs, but to be more informed citizens. Instead of teaching all students mathematics they may struggle to apply in the world, the certification and non-STEM tracks aimed to establish an immediate relationship between classroom and life. This connection is where quantitative literacy is specifically utilized. The new course, Quantitative Literacy (MAT 143), now fulfills mathematics requirements for nonSTEM students matriculating through the two non-STEM tracks (i.e., those seeking an Associate degree, Associate in Applied Science, college transfer, or certification), although some certification-seeking students may instead complete a non-transferable class. In general, students who have started in a STEM path may easily change paths to a non-STEM path with little to no need to take an additional mathematics class. Students who have chosen a non-STEM path and decide to change to a STEM path need to begin with pre-calculus algebra unless they need developmental coursework or they need to be placed into more advanced courses in the track. There are a few degree-specific university programs that still require more specific mathematics classes, but these programs are limited in number.

These new tracks are similar in spirit to The New Mathways Project ${ }^{1}$ through The Charles A. Dana Center, AMATYC's New Life Project (Rotman 2013), and the Statway and Quantway programs ${ }^{2}$ developed by the Carnegie Foundation. However, there is a slight difference between the revised track-based system implemented by the NCCCS and some of the aforementioned projects in that those projects utilize different courses to satisfy the mathematics requirements for different non-STEM tracks, namely a statistics course and a quantitative literacy course. For the new NCCCS system, the new quantitative literacy course serves the needs of students in two of the three tracks.

The approximate percentage of students at SCC in each of the three tracks for the 2014-2015 academic year was 2\% for non-degree seeking track, 27\% for STEM track and $71 \%$ for non-STEM track. With the existing articulation agreement with the University of North Carolina System, Quantitative Literacy (MAT 143) would satisfy the liberal studies mathematics requirement for fouryear institutions in the system.

\section{Skills needed in Quantitative Literacy}

Once it was determined that a new quantitative literacy class would be required for some students enrolled in an NCCCS community college, it was necessary to identify what topics the course would include. According to de Lange (2003), the

\footnotetext{
${ }^{1}$ http://www.utdanacenter.org/higher-education/new-mathways-project/

2 http://www.carnegiefoundation.org/statway (accessed 5/6/2015) or http://www.carnegiefoundation.org/quantway (accessed 5/6/2015): "Pathways Improvement Communities: The Community College Pathways.”
} 
necessary mathematics skills common to many quantitative literacy courses includes concepts of quantity, relationships, and uncertainty. With this in mind, the CIP committee developed the following common-course library description:

This course is designed to engage students in complex and realistic situations involving the mathematical phenomena of quantity, change and relationship, and uncertainty through project- and activity-based assessment. Emphasis is placed on authentic contexts which will introduce the concepts of numeracy, proportional reasoning, dimensional analysis, rates of growth, personal finance, consumer statistics, practical probabilities, and mathematics for citizenship. Upon completion, students should be able to utilize quantitative information as consumers and to make personal, professional and civic decisions by decoding, interpreting, using and communicating quantitative information found in modern media and encountered in everyday life.

This description led to a set of student learning objectives (SLO) divided into four categories: Conquering Quantity, Dealing with Data and Uncertainty, Contending with Change, and Managing Money.

The SLO's were developed during the MAT 143/MAT 110 Workshop held in Blowing Rock, NC, on July 15-17, 2013, with both CIP committee members and additional mathematics faculty from other North Carolina community colleges along with the guidance of Eric Gaze, president of the National Numeracy Network and director of the Quantitative Reasoning Program at Bowdoin College. The MAT 110 course reference in the workshop title refers to Mathematical Measurement, and MAT 143 refers to the new Quantitative Literacy course. Mathematical Measurement (MAT 110) was included in the workshop title because it also changed to more of a focus on quantitative literacy.

The learning objectives developed in the workshop were as detailed as possible so that every community college in North Carolina would know the exact intent of Quantitative Literacy (MAT 143) (see Tables 1-4). Because NCCCS utilizes a common-course library, it was of utmost importance that there was little difference in the classes in their expected learning objectives but enough room for difference in delivery so that instructors could teach with a certain sense of autonomy.

Table 1: Learning objectives for Unit 1: Conquering Quantity

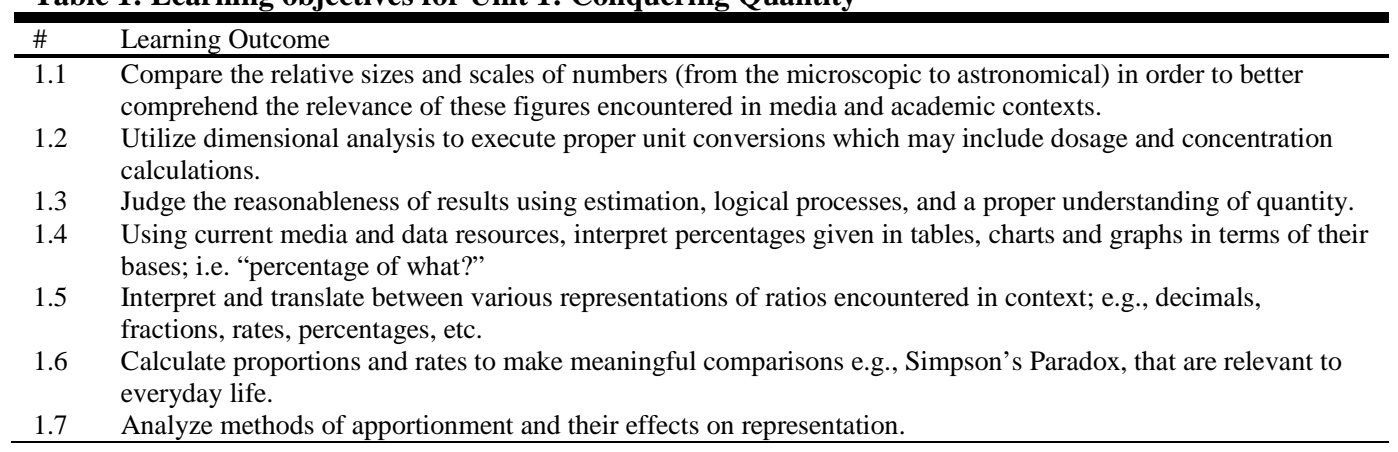


Table 2: Learning objectives for Unit 2: Dealing with Data and Uncertainty

\begin{tabular}{|c|c|}
\hline \# & Learning Outcome \\
\hline 2.1 & Compute experimental probabilities using basic laws of probability. \\
\hline 2.2 & $\begin{array}{l}\text { Given a two-way table of real world data, calculate probabilities involving AND, OR and NOT statements } \\
\text { and conditional probabilities. }\end{array}$ \\
\hline 2.3 & $\begin{array}{l}\text { Given the rate of occurrence of a disorder and sensitivity or specificity of a test for said disorder construct a } \\
\text { two-way table that models the number of occurrences for a given sample size. }\end{array}$ \\
\hline 2.4 & $\begin{array}{l}\text { Given real world probability data or odds relating to games of chance, insurance policies, etc, calculate the } \\
\text { expected value for a specified outcome. Use expected value to justify decisions for given scenarios. }\end{array}$ \\
\hline 2.5 & Describe data values in real world contexts using appropriate measures of central tendency and spread. \\
\hline 2.6 & $\begin{array}{l}\text { Given data from a media source, use technology to construct one or more of the following types of graphs: } \\
\text { histogram, box-plot, stack-plot, time-series, scatterplot or pie chart. }\end{array}$ \\
\hline 2.7 & Interpret a variety of basic and sophisticated graphics from media sources. \\
\hline 2.8 & $\begin{array}{l}\text { Given a mean and standard deviation of a distribution determine the } z \text {-score and percentile of a given data } \\
\text { point and communicate this information in a meaningful sentence. }\end{array}$ \\
\hline 2.9 & Explain the meaning of a poll or study that provides the margin of error and confidence level. \\
\hline 2.10 & $\begin{array}{l}\text { Compare and contrast observational and experimental studies and critique how the design influences the } \\
\text { conclusions drawn. }\end{array}$ \\
\hline
\end{tabular}

Table 3: Learning objectives for Unit 3: Contending with Change

\begin{tabular}{ll}
\hline$\#$ & Learning Outcome \\
\hline 3.1 & Compute and analyze rates of change (percentage, absolute, average) from selected tables and graphs. \\
3.2 & $\begin{array}{l}\text { Use growth rates to analyze quantitative data in various contexts including real world data, student-generated } \\
\text { data or data found in current media. }\end{array}$ \\
3.3 & $\begin{array}{l}\text { Use Interpolation and Extrapolation of real-world data and describe when each is appropriately used. } \\
\text { Critique the construction of graphs, charts and visual displays of quantitative information which may be }\end{array}$ \\
3.4 & $\begin{array}{l}\text { misleading. } \\
\text { Given linear and exponential data, interpret the rate of change within the given context. }\end{array}$ \\
3.6 & $\begin{array}{l}\text { Represent linear and exponential models as equations, tables, graphs and verbal descriptions. } \\
\text { Use technology to construct the appropriate linear or exponential models for sets of data and interpret the rate of }\end{array}$ \\
3.8 & $\begin{array}{l}\text { Identify data that models constant rates of change and explain the significance of either the absolute or relative } \\
\text { change. }\end{array}$ \\
3.9 & Using current media sources, describe the significance and implications of exponential growth or decay.
\end{tabular}

Table 4: Learning objectives for Unit 4: Managing Money

\begin{tabular}{ll}
\hline$\#$ & Learning Outcome \\
\hline 4.1 & Use the ideas of linear and exponential functions to develop the concepts of simple and compound interest. \\
4.2 & Calculate simple and compound interest. \\
4.3 & Show the difference between APR and APY. \\
4.4 & Model and analyze different savings plans and their outcomes. \\
4.5 & Use online tools to determine payments on consumer loans. \\
4.6 & Create amortization tables using technology, exploring various scenarios, and communicate conclusions. \\
4.7 & Ask appropriate questions about loan terms. \\
4.8 & Explore and analyze a variety of consumer loans considering individual budget constraints and communicate \\
& findings. \\
4.9 & Examine credit card terminology, perform basic credit card computations, and evaluate pay off options. \\
4.10 & Interpret financial terminology used by various types of media involving taxes, stocks, and bonds. \\
4.11 & Compute and compare income taxes for various situations such as income bracket, marital status, credits and \\
& deductions.
\end{tabular}

The initial plan of implementation was to teach some sections of MAT 140 (Survey of Mathematics), MAT 110 (Mathematical Measurement) and MAT 115 (Mathematical Models) using the new Quantitative Literacy syllabus during Fall 2013. In other words, during Fall 2013, no students officially got credit for MAT 143; however, the content material taught in these classes (MAT 140, MAT 110 and MAT 115) was that of the new quantitative literacy course. 


\section{Changing Pedagogy}

After much time and attention was devoted towards creating the learning objectives, classroom implementation needed to be determined. The amount of information that was required to be taught to satisfy the objectives far outweighed the amount of time that could be allotted in class for traditional lecture. Therefore, given that the essence of the quantitative literacy course was to be more collaborative, the pedagogy needed to change (Cuban 2001).

The choice was made to flip the classroom. At SCC, flipping the classroom consists of a three-part approach. First, students are to complete material that demonstrates a base level of knowledge before class, usually consisting of answering basic questions from the section that were related to the book and at times answering questions that were necessary for group work in the next class. Secondly, classroom time is spent developing these ideas on a deeper level through different labs (application-based material) usually including group work. Finally, students are given work to show proficiency in the material outside of the classroom. Students who are not prepared for class are generally grouped with other students who are not prepared. This approach to flip the classroom allowed for more hands-on work in class and less formal lecture time that hopefully will lead to less frustration of both students and instructors as seen in similar implementations elsewhere (Howington et al. 2015). This change was not only implemented on a local level at SCC, but was also the reason that a lab component was embedded in MAT 143.

An embedded lab allowed for more time in class for work without additional scheduled time allocated for a lab; that is, the contact time for the new course was the same as the courses that were replaced. The addition of an embedded lab allowed instructors the flexibility to lecture when needed, but also to work with student groups within class time. Labs are collaborative in nature, and taught students how to work together and to use available resources. For example, few employees in the financial sector use a formula for future value with a pen and paper, but a majority tends to use an online calculator or a future value option on a calculator or spreadsheet that implements the formula to determine the desired quantity. It was the norm in this new quantitative literacy class for an instructor to say "Let's Google that and see what comes up." Helping students understand what the numbers imply is different than teaching them how to derive the numbers.

The change in pedagogy was adopted to more effectively teach the quantitative literacy course to reflect reasoning skills needed in everyday life, since most people do not work where an employer delivers a traditional university lecture on how to do their jobs. This pedagogical change and resulting development of labs required an additional time investment for instructors toward the development of authentic contexts in which to apply the mathematics noted in the learning objectives. Thus, the majority of SCC instructors who taught 
Quantitative Literacy (MAT 143) allocated more time towards class preparation than might otherwise be spent in teaching a new course.

The amount of time that is required for adequate preparation for this new class is considerable on its own, but when coupled with the push for cooperative learning using data and information drawn from headlines, it can be quite an overwhelming time commitment. The most supportive part of the implementation was the development of the class. This collaboration has been the common theme throughout the implementation of Quantway, which can be seen as the developmental version of Quantitative Literacy through the National Network Improvement Community (Howington et al. 2015). At SCC, all labs and exams were agreed upon together, and they were changed as needed by the instructors involved in the implementation of the new course (a "pilot"). Undertaking such a change would have been more difficult without having others to be able to work through issues that inevitably arose. This collaboration existed not only within SCC but also across the state with other instructors sharing their class experiences through a conference call once a week.

One issue that arose in the discussions was the challenge of guiding students without leaving them with an overwhelming frustration level. This issue involved not only the classroom but also the written labs; guiding students is not what most instructors are accustomed to. There is a balance that must be found between allowing students to struggle and allowing students to reach the point of such frustration that they no longer continue. Students must be given adequate time to struggle with an idea but not so much frustration that success is lost altogether. Instructors and tutors must be able to see this balance and to not just inadvertently give students answers. To have guidance and experience of other instructors along the way was an invaluable tool to ensure that this balance was maintained. Quantway instructors recently shared a similar experience (Howington et al. 2015).

\section{Assessment in Quantitative Literacy (MAT 143)}

Flipping the classroom brought forth a whole new set of questions involving content delivery. A traditional class usually has work in class that is more "skill and drill"; that is, the teacher presents students a particular skill and then has them practice this skill in class. Given the nature of quantitative literacy and also the number of objectives, there was less time allowed for testing and more time provided for cooperative learning. Therefore, faculty across the state involved in the pilot were required to develop lab activities that involved real-world data and situations. These labs were designed to help teach and guide students through learning objectives with information that the students should already be familiar with before they arrived in class. Students then should be in a position to be able to work cooperatively together to understand the material. These labs are available for use by North Carolina mathematics community college instructors through a Blackboard website; the instructors can take advantage of this work as 
well as add to it. Some examples of labs used in the most recent iteration of MAT 143 are:

- Comparing different offers of financing a car.

- Identifying deceptive graphics with current graphs from news-related sources.

- Building amortization schedules employing different options for payoff.

- Examining diet with the use of USDA websites.

- Calculating income tax with current income tax forms.

- Interpreting medication concentrations related to exponential decay.

- Using dimensional analysis through medication with a true story of a trip to a hospital.

- Comparing steroid use in baseball before and after more drug testing by the baseball commission.

- Comparing student loans and tuition over the course of a student's academic career.

- Examining patterns in disability numbers over the course of many years.

- Analyzing where jobs were created in the most recent economic recession.

Every lab has an instructor and student page that lists the student learning objectives for that particular lab. For example, the first author wrote a lab about dimensional analysis that revolves around a medical story that happened to her grandmother. On the first page, the learning objectives 1.2 (Table 1: Utilize dimensional analysis to execute proper unit conversions which may include dosage and concentration calculations,) and 1.3 (Table 1: Judge the reasonableness of results using estimation, logical processes and a proper understanding of quantity) are listed on both the student and the instructor pages. The instructor page includes other relevant information such as materials required, time for completion, directions for instructor, scoring suggestions/grading rubric, text/unit reference and who submitted the lab. Therefore every instructor can easily link the objectives to the unit as well as any other material they may need.

To be able to continue to have a relevant connection to the world, the list of labs will continue to change from semester to semester. There will always be labs that can be used in some form every year but to be truly connected to the world, labs will need to evolve as new issues and new data emerge. Labs can also be adapted to individual school/class needs and to instructor preference. Therefore instructors can have the ability to adapt work to their own environment but also the availability to be able to work together and not be alone in this process. Presentation of material should be left to the instructor's discretion but, given that 
this process is so different for most instructors, being able to work together to develop material helps this process tremendously.

In the Fall 2014 semester, the Quantitative Literacy class was designed to use 21 labs during the semester. Most lab activities have a component that students are required to finish before class and a component to be finished as a collaborative effort together in class. Assessment of the labs varies according to instructor and can include individual and/or group grading. Most labs were designed to be completed within a two-hour class time, while some require three to four hours depending on content difficulty and lab length.

As always, instructors across the state had the flexibility to test as desired, but given the amount of material to cover in a semester, SCC chose to have two exams: a midterm and a final. In Fall 2014, SCC did change to include three exams. The reason for this change was the large amount of information that is required in Unit 1 (Conquering Quantity). Unit 1 is essential for a base of mathematics for the rest of the semester, but it includes a lot of information that is varied in application. Therefore, SCC decided to isolate this unit for testing.

\section{Change for all}

Change for Advisors. SCC approached the implementation of the new Quantitative Literacy class differently than other institutions. Most of the previous MAT 140 (Survey of Mathematics), MAT 110 (Mathematical Measurement) and MAT 115 (Mathematical Models) classes were combined into the new MAT 143 (Quantitative Literacy) during Fall 2013 and Spring 2014. After Fall 2014, SCC will continue to teach MAT 110 as Mathematical Measurement and Literacy. This will change MAT 110 to a quantitative literacy class with a focus on different non-degree seeking applications, but Survey of Mathematics (MAT 140) and Mathematical Models (MAT 115) will no longer exist as per the new articulation agreement.

All of these changes led to many questions for advisors and other nonmathematics instructors. Explaining quantitative literacy is in itself a difficult task as seen by the inability to determine a common definition. Therefore explaining the changes to advisors, faculty and staff at times was a challenge. Describing the concept of quantitative literacy to someone who has no education or background in it can come across as lofty until it is seen in practice. Advisors were also inundated with disgruntled students who were surprised on the first day of class by the prospect of going through the development of a new quantitative literacy class. Faculty and staff were receptive and supportive of the change even when at times it was not understood.

As a matter of fact, given that quantitative literacy has more reading and writing involved in the course, the opportunity has presented itself for instructors across the curriculum to work together to help students read, write and decode mathematics better. Mathematics instructors had to learn how to teach students how to write while also learning how to grade the writing themselves. Since the 
beginning of the pilot, faculty and staff have come to understand that the change was not in name only but truly a comprehensive effect.

Change for Students. Students who were expecting to have the same kind of math class they were accustomed to for years were not happy when they realized that this was not like any kind of math class they had ever taken before. No longer did students have the luxury of just showing up to class with no preparation expecting the teacher to lecture the whole time. Long teaching sessions were no longer necessary, but guidance of students in groups with short lectures was more appropriate. That structure can be disruptive to students who are accustomed to traditional mathematics instruction. The change in pedagogy requires more initial work for students, and students apprehensive about mathematics classes to begin with are not confident with the information they are learning on their own. These students, in particular, were afraid of answering math questions that did not appear to have clear-cut answers. The fact that less emphasis is on testing and more on classwork makes it impossible for a student to be successful in the course without participation in classwork and attention to preparation.

The content itself required more time for students to understand given that it involved relevant and current data. Students had to then begin to think differently and more independently, even when working in groups. Students were initially resistant to these changes. By the end of the semester, students were no longer excited over a lab that might have fewer questions, because they learned through the semester that fewer questions generally translated into more thought process. Students also became familiar with the questions that required words in multiple sentences or included the instruction "explain what this means" and expected these questions to be weighted more heavily.

Change for Tutors. One might assume that quantitative literacy would be easier to understand than other forms of mathematics. This notion is quite mistaken, as noted by The National Survey of America's College Students by the American Institutes for Research (Baer and Baldi 2006). Students who have excelled in higher levels of mathematics often remain unable to understand misuses of data or even be able to communicate or comprehend quantitative literacy (Steen 2001). Therefore, tutors who had excelled in previous classes found themselves at a loss when it came to tutoring quantitative literacy. Many times, tutors at SCC would meet with instructors to ensure that they understand the material. This effort was not due to a lack of intellect but a lack of understanding about how to critically assess information that is just assumed to be true in the media or elsewhere. Tutors had to be taught to go beyond what the answer was and explain what the answer means. This thought process is much different and more difficult.

\section{Polishing a Great Idea}

Students in the Fall 2013 pilot were overwhelmed with the amount of material presented. Therefore, the Spring 2014 iteration decreased the amount of material 
through a reduction in repetition while preserving content, and this change also presented a new challenge. The change was done by altering labs by diminishing the number of questions on repetitive content. The learning process for instructors in developing good labs that were data-driven was a challenge in the Fall 2013, and as a result, the Spring 2014 semester went smoother given the experience from the semester before. Having worked with students with the more difficult material gave guidance with adjusting questions and directions for labs. Looking forward to Fall 2014, adjustments have been made to provide a gentler introduction for students at the beginning of class with the understanding that students are adjusting not only to a flipped classroom, more group work, and a new integrated online homework system but also a different way of thinking. These adjustments have been made without sacrificing content or learning objectives.

\section{Analysis}

\section{Procedure}

SCC was asked to pilot the new Quantitative Literacy class during the Fall 2013 and Spring 2014 semesters before the community college system officially required Quantitative Literacy as a new class beginning in Fall 2014. This gave SCC a unique opportunity to be able to initiate the curriculum that would become a requirement for the Quantitative Literacy class across the system. During the Fall 2013 semester, SCC piloted six sections of Quantitative Literacy that included students who were registered for MAT 110 (Mathematical Measurement), MAT 115 (Mathematical Models) and MAT 140 (Survey of Mathematics). Piloted classes in the Fall 2013 semester were taught by three different instructors. There were four sections of MAT 140 that were taught in the traditional format by three different instructors. The teaching of these ten classes and sections was done without notifying students that there would be any curricular difference among the courses and sections of the affected courses. During the Spring 2014 semester, there were seven sections of the official Quantitative Literacy course (now numbered MAT 143), with four instructors and one traditional MAT 140 section.

The learning outcomes desired of students were assessed with the Quantitative Literacy and Reasoning Assessment (QLRA) distributed by The Science Education Resource Center (SERC) ${ }^{3}$ and described in Gaze et al. (2014). The assessment was built by "leaders and experts in the QLR field with extensive backgrounds working with SIGMAA-QL, the National Numeracy Network (NNN), and assessment to create an online resource for assessing QLR.” The QLRA is composed of twenty quantitative questions as well as demographic and attitude questions. The demographics included gender, ethnicity, intended major

\footnotetext{
${ }^{3}$ http://serc.carleton.edu/qlra/index.html: Quantitative Literacy and Reasoning Assessment (accessed May 21, 2014)
} 
or program, and mathematics courses presently or previously taken. The questions range from simple to more complex and are based on real-world data and scenarios. The QLRA questions include an assessment of the topics below:

- Ratios

- Conversions

- Decimals and Fractions

- Percentages

- Interpreting Tax Tables

- Misleading Graphs

- Solving Equations

- Interpreting Linear Growth

- Probability

- Interpreting Basic Statistics

There were five attitude questions where student responses were measured using a Likert scale with responses ranging from 1 to 5 according to strongly disagree, disagree, neutral, agree or strongly agree, respectively, with the statements below.

- Numerical information is very useful in everyday life.

- Numbers are not necessary for most situations.

- Quantitative information is vital for accurate decisions.

- Understanding numbers is as important in daily life as reading and writing.

- It is a waste of time to learn information containing a lot of numbers.

\section{Analysis of Covariance for QLRA Results}

The QLRA data from Fall 2013 were analyzed using an analysis of covariance with post-test score as the response variable, pre-test score as the covariate and an indicator variable for pilot enrollment. An initial consideration was to use the difference between the post- and pre-test as the response variable; however, this approach is equivalent to the analysis of covariance model defined above with slope of unity between post-test and pre-test scores, which is a more restrictive assumption (Cronbach and Furby 1970). The analysis of covariance model provides an estimate of the post-test treatment effect due to pilot enrollment, while controlling for possibly unequal pre-test scores between the pilot and traditional groups. It should be noted that pre-test scores and demographic information were all observed on the first class day and prior to any course instruction, so they were unaffected by any treatment conditions imposed by pilot or traditional course enrollment. This assumption is essential for an analysis of covariance model (Kutner et al. 2004).

Several analysis of covariance models were considered; the most promising of these was 
where

$$
Y_{(i, j)}=\mu .+\tau P_{(i, j)}+\gamma C_{(i, j)}+\epsilon_{(i, j)},
$$

$Y_{(i, j)}$ represents the post-test score for student $j$ in group $i$;

$X_{(i, j)}=\left(x_{(i, j)}-\bar{x}\right)$ where $x_{(i, j)}$ represents the pre-test score for student $j$ in group $i$ and $\bar{x}$ represents the overall mean of pre-test scores across groups;

$P_{(i, j)}$ is an indicator variable for pilot class enrollment, where $P_{(i, j)}=1$ if the student is enrolled in the pilot quantitative literacy class and $P_{(i, j)}=0$ otherwise,

$C_{(i, j)}=X_{(i, j)} * P_{(i, j)}$ is an interaction term, and

$\epsilon_{(i, j)}$ represents the random error component for student $j$ in group $i$.

The fitted model used $n=102$ observations and allowed the post-test to vary with the pre-test covariate, but only in the pilot group. The effect of the pilot was significant $(b=1.80, F(1,99)=7.35, p=.0079)$, while the slope for the pilot group modeling the association between the post-test results and pre-test results was also moderately significant $(b=0.39, F(1,99)=5.18, p=.0250)$. The $R$ squared for this model was .1111. A graph of this model is provided in Figure 1. A Shapiro-Wilk normality test of the residuals was nonsignificant $(W=.97971, p$ $=.1069)$ and a test for equal variances was nonsignificant $(F=.8358, F(47,53)=$ $1.595, p=.5336)$, thus, the sample model residuals did not violate assumptions of normality with equal variances between groups.

Figure 1. Analysis of covariance model in Equation 1: non-parallel slopes model with no association between pretest and post-test scores for non-pilot group. The non-pilot group observations are in red and the pilot group observations are in green.

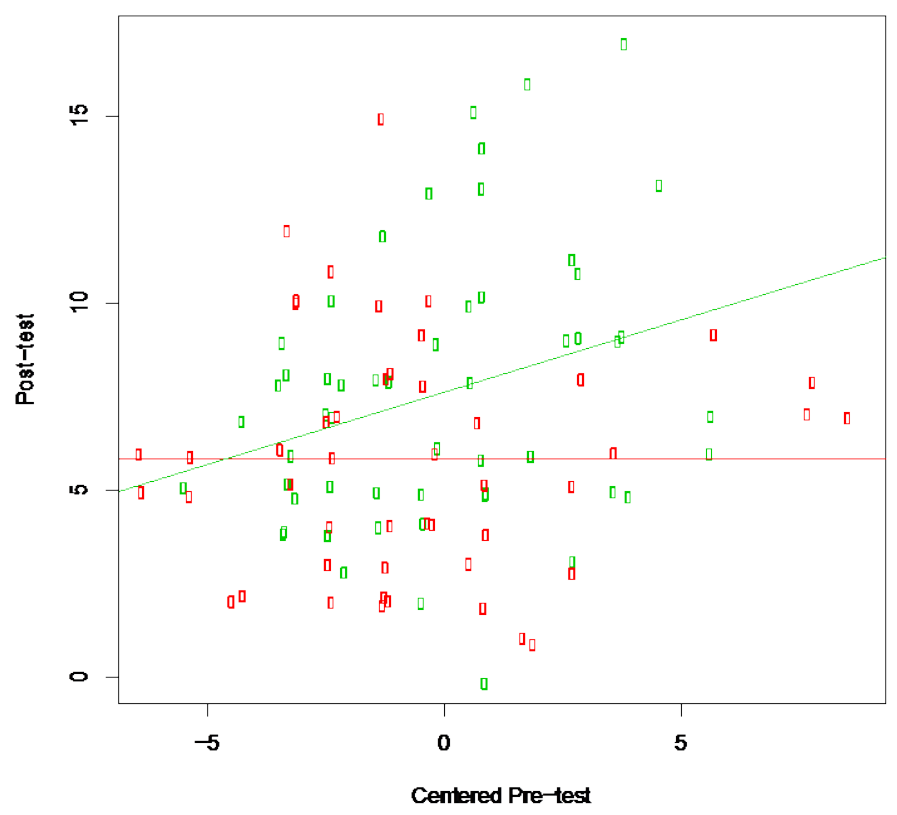


One of the limitations of this analysis was that students were not randomly assigned to the quantitative literacy pilot or traditional class. However, a comparison of pre-test scores between the pilot and traditional classes showed no significant difference $(d=.535, t(100)=.889, p=.376)$. The choice of class and section may have been due to any number of factors including seat availability, class schedule constraints, preferences for teachers, or delivery method (online or face-to-face). Additionally, one instructor taught a face-to-face version of the pilot and an online version of the traditional class, but this was the only instructor who taught both pilot and traditional classes.

\section{Attitudes Analysis}

There were five questions in the QLRA assessment that asked about beliefs about numbers. In Spring 2014, students were asked their opinion during the pre-test and the post-test using a Likert scale from 1 to 5 or from strongly disagree to strongly agree, respectively. Intuition would suggest that students in the pilot would agree more with the usefulness and applicability of numbers at the end of the semester. Therefore, the belief would be that the mean of the answers would be different after the pilot than before. To test this notion, a $t$-test was calculated for the data for each question. Note that questions 2 and 5 were both worded negatively, so that students who felt more positive about quantitative literacy responded lower on the Likert scale and thus the one-sided alternative was that the mean pre-test score was greater than the mean post-test score for these two questions. Questions 1, 3 and 4 were worded positively so that the one-sided alternative was that the mean pre-test score was less than the mean post-test score for these two questions. A summary of the paired $t$-test results is provided in Table 5 and a short summary of these results is provided below.

Table 5: Paired t-test comparisons for attitudes analysis.

\begin{tabular}{|c|c|c|c|c|}
\hline Question & Pre M(SD) & Post M(SD) & t-statistic (p) & Alternative \\
\hline $\begin{array}{l}\text { 1. Numerical } \\
\text { information is very } \\
\text { useful in everyday } \\
\text { life. }\end{array}$ & $4.24(0.87)$ & $4.13(0.87)$ & $\begin{array}{l}t(53)=-0.75 \\
(.7708)\end{array}$ & $\mu_{\text {Pre }}<\mu_{\text {Post }}$ \\
\hline $\begin{array}{l}\text { 2. Numbers are not } \\
\text { necessary for most } \\
\text { situations. }\end{array}$ & 2.48(1.09) & $2.52(1.11)$ & $\begin{array}{l}t(53)=0.20 \\
(.5806)\end{array}$ & $\mu_{\text {Pre }}>\mu_{\text {Post }}$ \\
\hline $\begin{array}{l}\text { 3. Quantitative } \\
\text { information is vital } \\
\text { for accurate } \\
\text { decisions. }\end{array}$ & $4.09(0.71)$ & $3.87(0.90)$ & $\begin{array}{l}t(52)=-1.77 \\
(.9584)\end{array}$ & $\mu_{\text {Pre }}<\mu_{\text {Post }}$ \\
\hline $\begin{array}{l}\text { 4. Understanding } \\
\text { numbers is as } \\
\text { important in daily } \\
\text { life as reading and } \\
\text { writing. }\end{array}$ & $4.22(1.13)$ & $4.33(0.77)$ & $\begin{array}{l}t(54)=0.63 \\
(.2637)\end{array}$ & $\mu_{\text {Pre }}<\mu_{\text {Post }}$ \\
\hline $\begin{array}{l}\text { 5. It is a waste of } \\
\text { time to learn } \\
\text { information } \\
\text { containing a lot of } \\
\text { numbers. }\end{array}$ & $1.96(1.14)$ & $2.19(1.17)$ & $\begin{array}{l}t(51)=1.15 \\
(.8718)\end{array}$ & $\mu_{\text {Pre }}>\mu_{\text {Post }}$ \\
\hline
\end{tabular}


Overall, there was not strong significance of change found in student opinions from the beginning to the end of the semester. However, with regard to statements 1, 3 and 4, students felt strongly about the importance of quantitative literacy at the start of the course, and, for the most part, students did not feel much differently at the end of the course. Overall, this result is encouraging given that if students can see a need for the class then they will be readily engaged.

\section{Conclusion}

The initial understanding of quantitative literacy at first glance appears to be simple. Instructors can see the importance, and, as seen by the students' initial attitude scores, convincing them that quantitative literacy is important is not an issue. Implementation is the difficult part, when students are asked to believe that frustration will lead to learning and instructors need to have data that is relevant and fresh. To change the way that mathematics is thought about from every perspective is simply difficult, but it is the most rewarding work a mathematician can do as seen not only by instructors in North Carolina but also other similar implementations across the country (e.g., Howington et al. 2015).

SCC is encouraged to see the glimpse of hope that this pilot may have made a difference in student learning. Beyond that, instructors were given the opportunity to be able to work together to dissect information in a way that students could understand it, and to be able to replicate it is one of the best teaching tools an instructor could be given. The professionals that worked together to make the pilot even a glimmer of success taught each other an enormous amount of information that is not found in any educational textbook.

Learning how to encourage students to think beyond what they had been asked for in the past without pushing them away is a skill that improved through experience. It is encouraging to know that these students will be able to make better financial, political, and informed decisions and will therefore be more prepared citizens. As an example, at the end of the Spring 2014 semester, students were asked what is the one thing that you learned in class that you will use in your daily life that you were not aware of before this class? One student responded:

Numbers in the media and percents [sic]! I was able to end an argument on Facebook with my brother about the amount of people in Buncombe County that are on food stamps. WLOS reported that 22,000 people from that county received EBT assistance and my brother thought that was a huge amount. This sparked a long discussion between him and his friends. So, I went online, found the latest county population, and figured what percent that would be, posted this to his feed and it stopped the debate. Then everyone questioned me as to how I figured it out. Yes, 22,000 people does sound like a lot but you have to know what the population (Base) is. I think it ended up being 8.8\%, which isn't as much as they thought it was when you figure in the county population. 
The truth is, before the quantitative literacy class this student would have believed what the media had presented was outrageous, but with the understanding of where numbers come from she was able to put the numbers into perspective for herself. Maybe if more students had been taught how to correctly look at financial data, the United States would have avoided the biggest economic downturn since the Great Depression. We have hope.

\section{Acknowledgments}

We would like to thank Dr. Julie Barnes and Dr. Kathy Jaqua for serving on the Master's Project committee of the first author and providing many helpful comments on this manuscript. We would also like to thank Hilary Seagle for allowing the opportunity to be a part of the pilot of MAT 143 and mentoring during the process. We learned an incredible amount of invaluable information including but not limited to implementing curriculum, working with groups of students, and writing labs.

\section{References}

Baer, J., Cook, A., and Baldi, S., eds. 2006. The Literacy of America's College Students. The National Survey of America's College Students. American Institutes for Research. http://www.air.org/sites/default/files/downloads/report/The20Literacy20of20 Americas20College20Students_final20report_0.pdf (accessed July 22, 2014).

Bressoud, D. 2009. Establishing the quantitative thinking program at Macalester. Numeracy 2(1): Article 3. http://dx.doi.org/10.5038/1936-4660.2.1.3 (accessed July 22, 2014).

Carnevale, A. and D. Desrochers. 2003. The democratization of mathematics. In Madison and Steen 2003, 21-30.

Cohen, P. 2003. Democracy and the numerate citizen: Quantitative literacy in historical perspective. In Madison and Steen 2003, 7-20.

Cronbach, L. and L. Furby. 1970. How we should measure "change" - or should we? Psychological Bulletin 74(1): 68-80. http://dx.doi.org/10.1037/h0029382

Cuban, L.2001. Encouraging progressive pedagogy. In Steen 2001, 87-91.

de Lange, J. 2003. Mathematics for literacy. In Madison and Steen 2003, 75-89.

Gaze, E. 2014 Teaching quantitative reasoning: A better context for algebra. Numeracy 7(1): Article 1. http://dx.doi.org/10.5038/1936-4660.7.1.1

—, Montgomery, A., Kilic-Bahi, S., Leoni, D., and Misener, L. 2014. Towards developing a quantitative literacy/reasoning assessment instrument. Numeracy 7(2): Article 4. http://dx.doi.org/10.5038/1936-4660.7.2.4 (accessed February 26, 2015)

Howington, H. Hartfield, T., and Hillyard, C. 2015. Faculty viewpoints on teaching Quantway. Numeracy 8(1): Article 10. http://dx.doi.org/10.5038/1936-4660.8.1.10 (accessed February 26, 2015). 
Kutner, M., Neter, J., Nachtsheim, C. and W. Li. 2004. Applied linear statistical models. Columbus: McGraw-Hill/Irwin.

Madison, B. L. and L.A. Steen, eds. 2003. Quantitative literacy: Why numeracy matters for schools and colleges. Princeton, NJ: National Council on Education and the Disciplines http://www.maa.org/sites/default/files/pdf/QL/WhyNumeracyMatters.pdf (accessed May 15, 2015).

Mathematical Association of America. 1994. Quantitative reasoning for college graduates: A complement to the standards. http://www.maa.org/programs/faculty-and-departments/curriculumdepartment-guidelines-recommendations/quantitative-literacy/quantitativereasoning-college-graduates (accessed May 22, 2014).

NCCCS. See North Carolina Community College System.

North Carolina Community College System. Math Pathways CIP (Curriculum Improvement Project) 2012-2014. http://www.successnc.org/initiatives/math-pathways-cip-curriculumimprovement-project-2012-2014 (accessed August 14, 2014).

Rocconi, L., Lambert, A., McCormick, A. and S. Sarraf. 2013. Making college count: An examination of quantitative reasoning activities in higher education. Numeracy 6(2): Article 10. http://dx.doi.org/10.5038/1936$\underline{4660.6 .2 .10}$

Rotman, J. 2013. Inside a new life: A grand vision for developmental mathematics. MathAMATYC Educator 4(3): 27-35.

Sikorskii, A., Melfi, V., Gilliland, D., Kaplan, J. and S. Ahn. 2011. Quantitative literacy at Michigan State University, 1: Development and initial rvaluation of the sssessment. Numeracy 4(2): Article 5. http://dx.doi.org/10.5038/19364660.4.2.5

Steele, B. and S. Kilic-Bahi. 2010. Quantitative literacy: Does it work? Evaluation of student outcomes at Colby-Sawyer College. Numeracy 3(2): Article 3. http://dx.doi.org/10.5038/1936-4660.3.2.3

Steen, L.A. (Exec. Ed.). 2001. Mathematics and democracy: The case for quantitative literacy. The Woodrow Wilson National Fellowship Foundation, National Council on Education and the Disciplines. http://www.maa.org/sites/default/files/pdf/QL/MathAndDemocracy.pdf (accessed May 15, 2015).

United States Department of Education. 1983. A Nation at risk. https://www2.ed.gov/pubs/NatAtRisk/risk.html (accessed May 22, 2014). 